\title{
Can Differences in the Ability to Recognize Words Cease to Have an Effect Under Certain Reading Conditions?
}

\author{
Emilio Sánchez, José-Ricardo García, and António-José Gonzalez
}

\begin{abstract}
In this study, we aimed to ascertain whether it is possible to create reading contexts that eliminate the impact of word recognition on reading comprehension and permit pupils with reading disabilities (RD) to attain a level of comprehension similar to that of their peers without RD. Specifically, the study compared a traditional reading situation with one of reading with aids (joint reading). In both situations, pupils' comprehension level was assessed by means of a summary and a series of inferential questions, and we controlled the effect on comprehension of word recognition, previous knowledge, rhetorical competence, and working memory. The results showed that the aids provided during reading do not eliminate the effect of word recognition, but they do permit readers with RD to attain a comprehension level similar to that of their peers.
\end{abstract}

$\mathrm{T}$ he study of the relationship between word recognition ability and text comprehension ability is crucial to an understanding of both the nature and development of literacy (see Gough \& Tunmer, 1986; Perfetti, 1985) and the problems of pupils with serious disabilities in these two areas. Our aim in the present study was to help clarify this relationship and to throw some light on the needs of pupils with word recognition problems (and how to meet those needs).

More specifically, we set out to assess whether offering pupils a context of help that facilitates their access to the meaning of texts allows the elimination of the effect of word recognition on reading comprehension. Favorable results in this direction would provide support for the need to design reading conditions similar to those tested here that give pupils with word recognition problems the opportunity to maintain contact with the printed word and to increase their exposure to print (Stan- ovich, 1986). We begin by reviewing research findings on the relationship between word recognition and reading comprehension. This is followed by a review of approaches to intervention for pupils with word recognition disabilities.

\section{Word Recognition and Comprehension}

According to Gough's simple view of reading (Gough \& Tunmer, 1986), the ability to identify words accurately and rapidly, together with the general capacity for understanding language, explains practically all the variability shown by readers in their level of written text comprehension. More specifically, in the view of Frederiksen and Warren (1987), word recognition and comprehension are related through a double mechanism. First, the more automatic the lexical access processes, the more cognitive resources can be in- vested in text comprehension; this is the principle underlying the verbal efficiency theory (Perfetti, 1985; see Note 1). Second, the swifter and more accurate the reading, the greater the continuity and reliability of the data with which the comprehension processes have to operate (see Note 2).

Despite a broad consensus on the aforementioned arguments, empirical analysis of the relationship between word recognition and comprehension does not show such a clear picture. Thus, grouping the existing research according to the methodology employed, the following conclusions can be drawn:

1. In studies comparing readers with different levels of comprehension in English (e.g., Bell \& Perfetti, 1994; Perfetti \& Hogaboam, 1975) and in Spanish (Cuetos, Domínguez, Miera, \& de Vega, 1997; Domínguez Martínez \& Cuetos Vega, 1992), it was found 
that readers with higher levels of comprehension do indeed read faster and more accurately than those with lower comprehensionthus indicating some kind of relationship between word recognition and comprehension.

2. In research designed according to instructional methodology-word recognition is taught, and its effects on comprehension are observedthe results have varied. For example, Fleisher, Jenkins, and Pany (1979); Jenkins, Barksdale, and Clinton (1978); Samuels, Dahl, and Archwamety (1974); and van den Bosch, van Bon, and Schreuder (1995) found no substantial improvement in comprehension when the intervention with readers is aimed at increasing the speed and accuracy of their reading; in contrast, this effect was indeed found by Blachman et al. (2004) and Tan and Nicholson (1997) and is mentioned in Pressley's (2000) review.

3. Finally, among correlational studies, aiming at measuring the impact of different variables (including word recognition) on comprehension, there have also been discrepancies; for example, whereas the results of Oakhill, Cain, and Bryant (2003) suggested that word recognition does not significantly explain variation in comprehension, in the work of Jenkins, Fuchs, van den Broek, Espin, and Deno (2003b); Joshi and Aarón (2000); Sánchez, Gonzalez, and García (2002); and Sánchez and García (2003), word recognition does indeed have a significant effect on comprehension.

Given these findings, some possible explanations for the relative lack of homogeneity of results can be suggested:

1. The first of these derives from the way comprehension is assessed. As Tan and Nicholson (1997) pointed out, some studies have used tasks such as semantic verification of sentences (e.g., van den Bosch, van Bon, \& Schreuder, 1995), instead of requesting participants to read passages, and this can weaken the possible relationship between the two abilities and explain why in some of these studies, such a relationship has not been supported. Bell and Perfetti (1994) concluded, based on results obtained with texts of varying degrees of difficulty, that word recognition skills are more relevant when the texts are difficult (an element that is not always controlled), as this determines a more advantageous distribution of cognitive resources.

2. It has also been argued (e.g., VidalAbarca, 2002) that not all studies control for the influence of variables closely related to the two abilities under study (e.g., previous knowledge, working memory, or linguistic development). It would seem obvious that the relationship between the two abilities should be verified even when they are under the control of other important variables. Otherwise, the influence of the word recognition variable could be further reinforced by other variables, which would make it relatively simple to yield results in favor of the relationship assessed.

3. The age at which this relationship is tested varies in different studies, and this may also help explain the discrepancies found: In very young participants, variability may be quite high, whereas the opposite is the case with participants at the older end of the scale. Indeed, some correlational studies (e.g., Oakhill, Cain, \& Bryant, 2003), working with very young children (7-8 years old at the beginning of their research), discarded the best and worst readers (see Note 3); this is an understandable decision, but one that may cloud the relationship analyzed.

In this context, our study may well clarify the relationship between word recognition and comprehension under particularly stringent conditions:

1. We control the impact of three variables with a recognized effect on comprehension: previous knowledge, working memory, and rhetorical knowledge of texts.

2. The relationship in question is verified under two reading conditions, giving rise to two levels of difficulty in the same text: a condition with aids, or joint reading; and a traditional condition, with no additional help.

3. Participants have 6 years' education (i.e., they are at a significant point of transition as regards literacy) and were selected at random and without setting any ability level criteria for their inclusion in or exclusion from the analyses.

Under these conditions, the outcomes of our study will have theoretical interest whatever their nature and direction. Three possibilities can be anticipated:

1. We do not find a relationship between word recognition and comprehension, after segregating the effects of the three control variables, in either of the reading conditions. In this case, the need to consider this type of control variables in studies on this subject would become evident.

2. A relationship between word recognition and comprehension (after segregating the effects of the three control variables) is confirmed in both the conventional reading condition and the condition with aids. In this case, the results could be taken as strongly supporting the relationship between the two abilities.

3. A relationship is found only in the traditional reading condition (without aids), and not in the condition with aids. In this case, it could be argued that the relationship between the two variables is 
solid but controllable, and this reinforces our approach.

It should be pointed out that both Outcomes 2 and 3 would raise the problem of how to help readers with word recognition disabilities overcome the relationship (seriously limiting to them) between word recognition and comprehension. However, if the results were to coincide with the scenario described in the third of these possible outcomes, we would have found a way to help them. In contrast, if the results fitted the situation described in the second possibility, we would still have to find a solution. In any case, to put the possible consequences of this study in context, we should first review how the needs of readers with word recognition disabilities are addressed.

\section{Intervention in Reading Difficulties}

Most of the research on learning disabilities has been aimed at identifying as accurately as possible the specific deficits that are responsible for reading difficulties and designing equally specific interventions for correcting and compensating for them. Thus, to explain the problems in word recognition, different nuclear deficits have been postulated, and evidence in support of them provided-one such case being that of the deficit in phonological awareness (Calvo, 2000; Catts, 1989; Ellis, 1990; Felton, 1992; Jiménez, 1997; Rack, Snowling, \& Olson, 1992; Stanovich, 1988; Stanovich \& Siegel, 1994; Wagner \& Torgesen, 1987; Wagner, Torgesen, \& Rashotte, 1994). Likewise, although there is less evidence available, it has been postulated that there is another deficit associated with word recognition-that of naming speed (Bowers \& Wolf, 1993; Wolf, 1991). This has led to the hypothesis of a double deficit associated with reading disabilities (RD; Wolf \& Bowers, 1999)—one phonological and the other linked to the recovery of lexical information. Consequently, treatments adjusted to each of these potential deficits have been de- veloped. With regard to the phonological type of deficit, proposals have been abundant (Hatcher, Hulme, \& Ellis, 1994; Hernández-Valle \& Jiménez, 2001; Lovett, Borden, et al., 1994; Olson, Wise, Ring, \& Johnson, 1997; Rueda \& Sánchez, 1996; Sánchez \& Rueda, 1991; Torgesen et al., 1997; Vellutino, Scanlon, \& Lyon, 2000; for a review, see Troia, 1999). Similarly, although the treatments involved are more recent, proposals have been made that consider the naming speed deficit hypothesis (Lovett, Steinbach, \& Frijters, 2000), and the effect of this deficit on the results of intervention has been studied (Allor, Fuchs, \& Mathes, 2001). Finally, efforts are under way to isolate other abilities-such as speech perception (Joanisse, Manis, Keating, \& Seidenberg, 1999), paired associated learning (Windfuhr \& Snowling, 2001), and phonological and executive systems in working memory (Swanson \& Hovell, 2001) — that in the future may help to explain RD in certain readers and point the way toward possible treatments for them (see Note 4).

However, this line of intervention is slow and laborious because, while readers make progress in the solution of their specific difficulties of word recognition, they have to continue reading texts that-given the effort invested in word recognition-will be difficult for them to understand and will distance them from contact with the printed word, the only way of counteracting the so-called Matthew effect (Stanovich, 1986). One proposed solution is balanced instruction (e.g., Klenk \& Kibby, 2000; Torgesen, 2002), which combines treatments aimed at improving word recognition with the teaching of comprehension strategies. However, in our view, this alternative does not prevent pupils with RD from having to endure considerable hardship before they succeed in mastering the strategies that enable them to understand what they read, and only then (perhaps) make sense of the effort invested. The challenge, therefore, is how to achieve success in reading from the outset.
Thus, in the present study (without challenging the previous line of thinking, which we indeed believe to be essential), we attempt to offer evidence in favor of a type of complementary intervention that recovers in part some of the arguments set out by those authors interested in preserving a communicative view of written language (see, e.g., Goodman, 1990). There are some well-founded criticisms of this position (for a review, see Pressley, 1999), but there is one aspect of this communicative conception that is certainly worth rescuing: the need to guarantee that pupils with word recognition disabilities can, in spite of this severe limitation, accede to the gratifying experiences that texts provide to good readers.

In this regard, our objective lies in exploring the possibility that under certain reading conditions (created with a given number of aids potentially applicable to any text), the differences and difficulties in word recognition that pupils may present would not affect the communicative use of texts. Precisely for this reason, we propose to determine what these satisfactory experiences might consist of, and to show their effects empirically. If this possibility were confirmed, we could consider enriching the intervention for pupils with RD by means of two types of complementary treatment: one aimed at the specific problem (be it processes of reading or comprehension) and another one at the communicative level.

Specifically, we propose to test a procedure we have called joint reading, which aims to offer pupils the aids necessary to reach a satisfactory level of comprehension. In more practical terms, we are interested in knowing whether an adequate combination of aids could eliminate the influence of word recognition on text comprehension or, at least, normalize the experience with texts for those pupils with serious word recognition problems. In the first case, we would have to show that the influence of word recognition ceases to play a role; in the second that, when pupils with RD read with the aids pro- 
vided by joint reading, they achieve the same level of comprehension as their peers without RD.

Thus, to summarize, we have developed a study in which we

1. analyze the impact of differences in word recognition on comprehension after segregating the effect of three variables: previous knowledge, working memory, and rhetorical competence-that is, the ability to operate with the structural aspects of text (Goldman \& Rakestraw, 2000);

2. compare the results of this analysis in two reading conditions: one without aids (traditional) and another with aids (joint reading); in the light of what we have discussed so far, the crucial question is whether the impact of word recognition is maintained in the two conditions or not;

3. check whether pupils with serious word recognition problems achieve the same performance in text comprehension in the joint reading condition as pupils without difficulties do when reading without aids (this is what we understand by normalization).

The optimum result for our approach would be as follows: The relationship between word recognition and text comprehension is maintained in the case of traditional reading (which would support the strength of the relationship), but it disappears in joint reading-in which, moreover, poor readers normalize their performance in comprehension. Nevertheless, it should be borne in mind that, as noted earlier, whatever the result obtained, the study will have theoretical and practical relevance (see Note 5).

Consideration of these objectives may lead to three misinterpretations that we should like to anticipate:

1. The present work might be seen as an instructional study, in which we proposed to test a procedure for teaching comprehension strategies to pupils with word recognition difficulties. Clearly, this is not our objective.

2. We do not simply expect the joint reading procedure to enable the poorest readers to improve their comprehension, which would of course bring nothing new whatsoever to the field. The novelty, if there is one, resides in showing that our help neutralizes the effect of differences in word recognition on comprehension or, at least, normalizes the experience with text of pupils with RD.

3. Nor do we aspire to a situation in which the joint reading experience eliminates the problems of word recognition. We simply expect that with a certain number of aids, the differences and difficulties in word recognition that characterize certain readers will cease to have an influence on the final result.

\section{Joint Reading to Guarantee Contact with Print}

Joint reading is based on two principles: First, the interpretation of texts is set out as a joint activity between students and teachers. In accordance with the possibilities of each reader and the difficulty of the text, a form of collaboration or distribution of responsibility is created (see Note 6). Teachers can thus make themselves responsible for the part of the interpretation process that the student cannot fulfill even with help. Second, from this initial distribution, a process of transfer of control can be initiated. For example, if the teacher begins by taking on the task of organizing the ideas in the text, in subsequent readings, the same task could be gradually passed on to the students (see Sánchez, 1998, for details).

The appropriate development of these principles depends on the aids that the teacher has for completing the reading process in areas that the student is unable to attain independently. Specifically, we have developed five types of aids, which are a reflection of the cognitive operations involved in the reading process (see Graesser \& Britton, 1996; van Dijk \& Kintsch, 1983). It is important to point out that these aids are well known in this research field, as they were designed on the basis of some of the reading strategies with the greatest empirical support for their relevance to text comprehensionnamely, summarizing or retelling, predicting, relating prior knowledge or personal experiences to the text, and setting a goal for the reading (e.g., Armbruster, Anderson, \& Ostertag, 1987, 1989; Brown, Pressley, van Meter, \& Schuder, 1996; Cole, 1997; Dole, Duffy, Roehler, \& Pearson, 1991; Palincsar \& Brown, 1984; Peeck, van den Bosch, \& Kreupeling, 1982; Pressley, 1976; Roehler \& Duffy, 1984). These strategies have constituted the content of numerous intervention programs and methodologies aimed at improving comprehension, the best known probably being direct explanation (Duffy et al., 1987; Roehler \& Duffy, 1984) and reciprocal teaching (Palincsar \& Brown, 1984). In turn, the review and implementation of these methodologies has given rise to variants and adjustments, such as the transactional explanation in the former case (Brown, et al., 1996) or Cole's (1997) sociocultural reinterpretation of the latter approach. However, in all of these programs, comprehension strategies are taught (usually following a sequence that includes the explanation of each strategy, its exemplification, supervised trials, and generalization activities), and their acquisition by the pupil constitutes the instructor's immediate objective. In contrast, in joint reading, the strategies adopt the form of aids that the teacher may provide for any text, according to the pupil's needs, and with the initial objective of guaranteeing comprehension. Thusalthough we shall not dwell on this point, as it goes beyond the scope of the present study-the accumulation of successful reading experiences will lay the foundations for the teaching of strategies. This teaching is understood as a process of explicitation and trans- 
fer of responsibility, in which the instructor allows pupils to gradually assimilate - and make their own - the strategies initially provided in a nonexplicit manner as aids.

The first type of aid (within the Ausubelian tradition) deals with the creation of a specific goal to justify and lead the comprehension process. Take, for example, the following sample text:

\section{The Mediterranean Is Dying}

The situation in the waters of the Mediterranean has been described by experts as alarming, and some have even talked about the imminent death of this historic sea.

With a surface area five times greater than Spain, and an average depth of 1,400 metres (which makes it a relatively small sea), its waters lap the shores of 18 countries, continually receiving the urban and industrial waste of more than 150 million people. If we also consider the refuse generated by the 100 million tourists who visit its coasts every summer-a number that could double over the next 25 years-it is clear that these waters are irredeemably condemned to become a foul sewer.

Given that the Mediterranean's waters are only replenished through the narrow straits of Gibraltar, they are unable to support all this waste, which includes the millions and millions of tonnes of highly contaminating, extraordinarily dangerous toxic waste that are pumped into thempetrol, mercury, lead, and so on. Furthermore, the dumping of organic materials and fertilizers is leading to the growth of massive algae colonies, which cause problems for many of the living things that inhabit the sea. (Sánchez, 1998, pp. 170-171)

For this text, the first type of aid can be offered as follows:

You are going to read a text that we think is very interesting because it talks about the Mediterranean and how it is dying [indication of what the text is about]. Sometimes we think that things we are familiar with-a mountain that we see from our window, or a river-are going to be around forever [reflection on what the students know]. This text makes us realize that this idea isn't totally correct [indication of what the text is about]. Why do we have to read the text? To understand why the Mediterranean is dying. How do we know that we have understood the text properly? When the causes are clear [indication of what the text is about, to regulate the reading].

Note that this aid involves alternating between what the readers may know about the subject and what the text can tell them.

The next three aids facilitate the clarification of ideas and their relationship, allowing the reader access to what the writer has in his mind-or, more accurately, access to what the teacher thinks is in the writer's mind. Thus, the second aid consists of offering the student a rhetorical scheme that articulates the different content and ideas that can be extracted. For example, returning to the sample text, the aid can be presented as follows: "This text explains that there are certain reasons, three in total, why this sea might disappear. Is that clear?"

The third aid reveals to the pupils, during reading, the different topics that are articulated through the text. For example, in our sample text, this would consist of showing that it first speaks about the contamination of the waters, then about their insufficient renewal, and finally about the proliferation of algae.

The fourth aid consists of clarifying for the reader what the text says (the macropropositions). For example, we could clarify the ideas that summarize some or all of the topics: the Mediterranean is being polluted by tourists, cities, and industry; its waters are insufficiently renewed because there is only a narrow strait linking the sea with the Atlantic Ocean; and so on.

Finally, the fifth aid consists of providing an opportunity for the reader to evaluate the comprehension attained: For example, the students could be asked why the Mediterranean is dying (literal evaluation) or what state they think the waters of other seas or oceans are in (inferential evaluation). They could also be encouraged to ask questions themselves (see Palincsar \& Brown, 1984).

As mentioned earlier, each reading situation, depending on the type of text and students, will require some of the aids and not others, creating different reading contexts. In the present study, we assess whether one of these possible contexts permits the achievement of the initial proposal-that is, to eliminate the effects of disabilities in word recognition or to offer pupils with RD experiences in reading comprehension similar to those of their peers. Thus, the novelty of this procedure resides not in the aids themselves (as we pointed out, all of them are well known and supported) but, rather, in showing whether it is possible to design reading situations with the aims described.

\section{Method}

Two reading situations were designedjoint reading, using some aids, and traditional reading, without their useand were compared in three steps:

1. Given that the situation of reading with aids would be more appropriate if it had an effect on the level of comprehension attained by all students, we experimentally checked the effectiveness of the joint reading condition.

2. In each situation, by means of a regression equation, we assessed the effect of word recognition once the following three variables had been controlled: (a) previous knowledge, (b) working memory, and (c) rhetorical competence.

3. We analyzed whether the comprehension level achieved by the pupils with $R D$ in reading with aids could be equated with that usually achieved by the other pupils when they read without help. However, this was an a posteriori analysis not initially envis- 
aged in the methodological design, so it will only be considered in the presentation of the results.

\section{Participants}

A total of 154 sixth-grade primary school students (11-12 years old; see Note 7) took part in the study, representing five primary schools in Salamanca, Spain. To obtain this sample, schools in Salamanca were grouped in five categories: (a) rural schools with low socioeconomic status enrollment, (b) rural schools with middle socioeconomic status enrollment, (c) urban schools with low socioeconomic status enrollment, (d) urban schools with middle socioeconomic status enrollment, and (e) urban schools with high socioeconomic status enrollment. We then contacted at random one school from each category to make up the sample of all sixth-grade pupils. Table 1 illustrates the diversity of the sample, although it should be borne in mind that we did not have access to data on the academic performance or intellectual ability of all the pupils. Each one of these pupils was randomly assigned (see Note 8) to one of two reading conditions.

\section{Reading Conditions}

Condition A: Traditional Reading. In this condition, pupils were asked to read the text "The Mediterranean is Dying" without any of the aids. They were simply told, "Read this text carefully, because we are sure that it will interest you. Pay attention, because later we'll ask you to write a summary and answer some questions." This condition has been referred to as traditional reading, because it has been observed in a large number of primary classes (Sánchez, Rosales, \& Suárez, 1999) that texts are read without any aid to direct the process, and after reading the students answer a series of questions.

Condition B: Reading With Aids $\mathbf{1}, \mathbf{2}$, and $\mathbf{3}$. Students in this condition also read the text but were additionally offered the first three aids: a precise goal, the rhetorical scheme for the text, and the clues necessary to identify the text's topics. The first two aids were presented orally (exactly as described earlier), but the third aid was presented in writing, inserted into the text. In contrast to the other aids, this aid should be applied-as stated previously-during the reading process, not before. Therefore, to present the aid verbally, it would be necessary to interrupt the reading. In this case, the second condition would be very different from the first, threatening the validity of the study (see Note 9). Therefore, we modified the text (only for pupils in Condition B) to clarify each of its topics:

1. Each topic developed was assigned a single paragraph

2. Each one of the causes was introduced with specific rhetorical markers: "one of these is ..., a second cause ...., there is a third factor ...," and so on.

3. Causal rhetorical signals were introduced. For example, the third paragraph tells us that the Mediterranean only renews itself "through the Straits of Gibraltar," and concludes, "this means that these waters ...." The expression this means that links the two ideas and confirms that the same topic is being referred to.

These modifications increased the length of the text by $25 \%$, but the new version maintains the same vocabulary and the same semantic content (as demonstrated in the procedure of Bovair \& Kieras, 1985).

\section{Dependent Variables}

The effect of each condition was measured through students' summaries of the text and through their response to a series of inferential questions. Both were written exercises.

Summary. For each summary, we considered two types of indicator: (a) number and type of ideas and (b) their organization. To calculate the number of ideas, the text was segmented into statement nodes (or propositional schemes, according to van Dijk \& Kintsch, 1983), each of which was classified as a causal or detail idea (in the terms of Graesser \& Goodman, 1985; Graesser \& Britton, 1996). Furthermore, with regard to the rhetorical structure of the text (see Figure 1), we differentiated between central causal ideas (each cause and its consequence; e.g., the death of the Mediterranean) and secondary causal ideas (the ideas that reflect the conditions reinforcing each cause; e.g., the fact that it is a small sea). This distinction is important, because the central causal ideas were especially highlighted by the aids given, whereas the secondary causal ideas were not. Thus, the effects of the experimental conditions-if there are any-should be identifiable in both cases, especially in that of secondary causal ideas. Finally, the detail ideas (the rest) refer simply to properties or facts, such as the size of the Mediterranean.

In grading the extent to which the summary reflected the causal organization of the text, we used a scale of 0 to 3 :

\begin{tabular}{lcc}
\hline \multicolumn{3}{c}{$\begin{array}{c}\text { TABLE 1 } \\
\text { Descriptive Statistics of Participants by } \\
\text { Reading Condition }\end{array}$} \\
\hline Measure & Condition A & Condition B \\
\hline Gender & & \\
$\quad$ Male & 40 & 42 \\
Female & 37 & 35 \\
SES & & \\
High & 22 & 13 \\
Middle & 34 & 42 \\
Low & 21 & 22 \\
Location & & \\
Urban & 58 & 60 \\
Rural & 19 & 17 \\
\hline
\end{tabular}

Note. Condition A = traditional reading; Condition B = joint reading; SES = socioeconomic status. All children were in general education classrooms. Most participants were Spanish, but there were a few participants of Hispanic or Calé origin.

a $N=77$ for both conditions. 


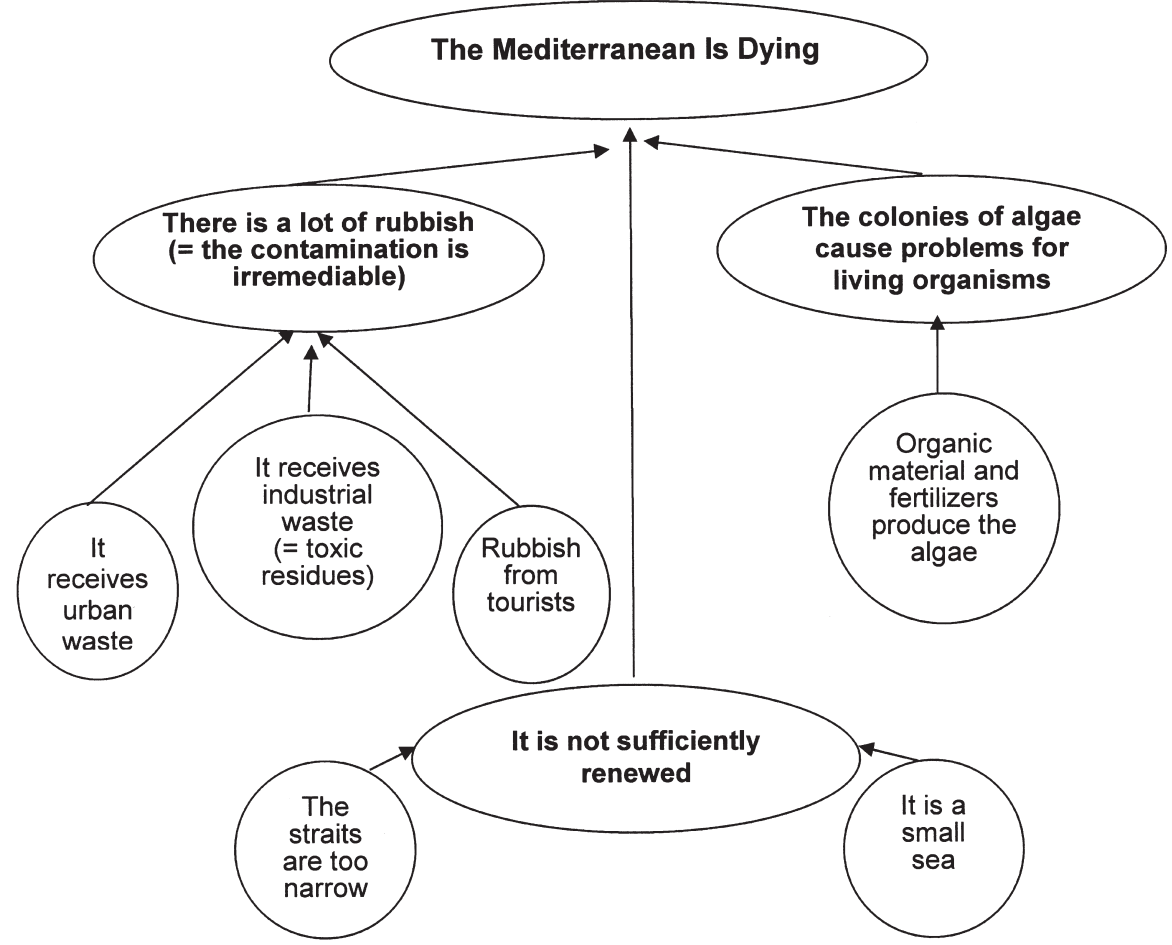

FIGURE 1. Causal ideas in the sample text "The Mediterranean Is Dying." The central causal ideas are shown in bold and the secondary causal ideas in regular print.

- 0 points if the ideas appeared as an unconnected list.

- 1 point if some kind of relationship was established between ideas, but not a causal one-that is, if structural markers such as "in the first place" or "also" appeared.

- 2 points if some kind of causal link appeared, but only in a general sense (not with each cause):

"The Mediterranean is dying because ..."

- Finally, 3 points if, in addition to the features described previously, the summary included specific causal connectors: "the first reason is that ...," "the second reason is ...."

Six of the summaries were selected at random. From discrepancies identified between the evaluations of three independent judges, the criteria for correction were widened, repeating the process until a reliability level of .9 was obtained. Finally, all the sumwith the criteria that proved the most reliable (i.e., those just described).

Inferential Questions. Pupils were asked to respond to four inferential questions:

1. Do you think the Atlantic is more or less polluted? Why?

2. What would happen if the Straits of Gibraltar were wider?

3. What would happen if the Mediterranean were shallower?

4. What would happen if the Mediterranean were smaller?

The responses given were scored on a scale from 0 to $2(0=$ responses that reflected errors of comprehension, e.g., believing that the Mediterranean would be more contaminated if it were larger; 1 = correct answers; 2 = responses that were both correct and accompanied by some reason or suitable argument). A reliability level of around
.9 was obtained following the procedure used in the evaluation of the summaries.

The inferential questions were designed to measure the situational representation (situation model) and the summaries to measure the textual representation (text base). After discussion among the judges, it was agreed that a suitable level of comprehension should reflect the attainment of the following criteria:

1. The summary should contain more causal ideas than detail ideas.

2. The organization of the summary should reflect to some extent the causal logic of the original text (the equivalent of 3 or 2 points in this indicator).

3. The student should be able to answer at least half of the inferential questions.

\section{Criterion Variable}

As a criterion variable for the regression equation, we took into account the number of causal ideas (central causal ideas plus secondary causal ideas) included in the summaries.

\section{Predictor and Intergroup Control Variables}

Previous Knowledge. We designed a bank of 14 items with which to assess how far the students' knowledge of various selected topics related to geology, geography, and history. Each correct answer was awarded 1 point using the criteria from the correction guidelines showing highest reliability (more than .9) when employed by three independent judges. After marking, the items that best correlated with the criterion variable were chosen. Thus, the final questionnaire consisted of seven questions, some on general knowledge (e.g., "What is an iceberg?" "What is a glacier?") and others about subjects closely linked to the text ("How wide do you think the Straits of Gibraltar are?").

At the same time, the previous knowledge variable acted as a predic- 
tor for the regression equation and as a control variable for intergroup equality. The same can be said for the following three variables: rhetorical competence, working memory, and word recognition.

Rhetorical Competence. Rhetorical competence refers to the capacity for interpreting the cues contained in the text (anaphora, structural markers, etc.) to establish linear and global relationships between the ideas. In an earlier study, we verified that this capacity has a specific influence on comprehension (Sánchez, Gonzalez, et al., 2002), as did Oakhill, Cain, and Bryant (2003) and Cain, Oakhill, and Bryant (2004) when they analyzed the effect on comprehension of different variables, among them knowledge of text structure (a variable very close to the definition of rhetorical competence, as will be seen). In the present study, out of two tests designed for measuring rhetorical competence, we used only the one with the greater explanatory potential. In this test, the students were asked to read 10 texts and then write a continuation to each of them. In this way, we evaluated not the quality of the writing but simply whether students had interpreted the rhetorical markers correctly. For each of the 10 items, 1 point was awarded for a correct response. The marking reliability of the test, as assessed by three independent judges, was 8 .

Working Memory. This variable was evaluated using Daneman and Carpenter's Reading Span Test (adapted to Spanish by Elosúa, García Madruga, Gárate, Gutiérrez, \& Luque, 1993), in which students have to read a progressively greater number of sentences (first one, then two, then three, and so on) and remember the last word of each sentence. The maximum score that can be obtained is 5 , when the last word of six sentences is remembered in three different items.

Word Recognition. We evaluated the precision and speed of word recognition through lists of words and pseudowords from the PROLEC-SE battery (Cuetos \& Ramos, 1997). In this way, we were able to measure the maturity of both access routes-lexical and phonological (Coltheart, 1978)by obtaining four different measurements: word reading speed, pseudoword reading speed, word reading accuracy, and pseudoword reading accuracy. All four measurements were used for controlling intergroup equality, but only word reading speed was selected to form part of the regression equation. This measurement showed the most significant correlation with the criterion variable $(p<.01)$ compared to pseudoword accuracy $(p=.01)$ and the other two measurements $(p>$ $.05)$.

Comprehension Measured by a Standard Test. To obtain another measurement for intergroup control (not as a predictor variable), a standardized comprehension assessment was carried out, using another subtest of the PROLEC-SE battery (Cuetos \& Ramos, 1997), in which pupils had to read two texts, "The Eskimos" and "The Australian Papuas," and answer some questions. Each correct answer was awarded 1 point, with a maximum score of 20 .

\section{Procedure}

The application of the evaluation instruments for each variable, the reading of the text in accordance with each of the experimental conditions, and the evaluation of the comprehension level attained took up three sessions in each school: two collective sessions lasting 1 hour each, and one individual session lasting approximately $15 \mathrm{~min}$. In the first collective session, once the students had been divided into groups to be assigned to each of the experimental conditions, their previous knowledge was evaluated. Next, the sample text "The Mediterranean Is Dying" was read, recreating the corresponding reading conditions, and finally the students were asked to summarize the text and answer the questions. The researcher giving the reading instruction was always the same person; at the same time, an observer ensured that in all schools the instructions and aids were the same.

The second collective session was devoted to the evaluation of rhetorical competence and comprehension level by means of the standardized test. Word recognition and working memory were evaluated in the individual session. All materials were presented in Spanish, this being the mother tongue of all the pupils participating in the study.

\section{Hypothesis}

Principally, we reviewed the hypothesis that the aids offered under Condition $B$ would reduce the impact on comprehension of word recognition speed. In other words, the word recognition variable would have a significant impact on the regression equation established in Condition A, but not (or at least not as much) in Condition B. However, as already stated, it is also necessary to review a prior hypothesisthat the students in Condition B will show better comprehension, evident both in the quality of their summary and in their responses to questions. In other words, in view of the criteria established, their summaries would be characterized by the inclusion of more causal ideas than detail ideas and by the use of causal linkages in the setting out of their ideas; at the same time, they should be able to answer at least half the questions correctly.

\section{Results}

An alpha level of .05 was used for all statistical tests.

\section{Intergroup Equality}

The variance analysis (ANOVA) confirmed that the two groups were statistically equal (see Table 2), with probability values ranging between .06 and .94 . 


\begin{tabular}{|c|c|c|c|c|}
\hline \multicolumn{5}{|c|}{$\begin{array}{c}\text { TABLE } 2 \\
\text { Means and Standard Deviations of Intergroup Control Variables by } \\
\text { Reading Condition }\end{array}$} \\
\hline \multirow[b]{2}{*}{ Variable } & \multicolumn{2}{|c|}{ Condition A } & \multicolumn{2}{|c|}{ Condition B } \\
\hline & $M$ & $S D$ & $M$ & $S D$ \\
\hline Previous knowledge & 2.7 & 1.6 & 2.7 & 1.4 \\
\hline Rhetorical competence & 5.2 & 2.2 & 5.2 & 2.2 \\
\hline Working memory & 1.4 & 0.6 & 1.3 & 0.6 \\
\hline \multicolumn{5}{|l|}{ Access routes } \\
\hline Accuracy & 38.2 & 2.7 & 38.7 & 1.4 \\
\hline Speed & 48.6 & 25.5 & 47.1 & 21.7 \\
\hline \multicolumn{5}{|l|}{ Phonological } \\
\hline Accuracy & 35.5 & 3.6 & 36.1 & 3.5 \\
\hline Speed & 82.0 & 51.0 & 69.0 & 34.0 \\
\hline Comprehension & 9.6 & 4.3 & 10.5 & 4.0 \\
\hline
\end{tabular}

Note. Condition A = traditional reading; Condition $\mathrm{B}=$ joint reading with Support Aids 1,2 , and $3 . \mathrm{N}=77$ for both conditions.

\section{Effect of the Reading Conditions on Comprehension}

The results in comprehension obtained for each group are shown in Table 3. The ANOVA and the analysis of Fisher's PLSD showed that the students in Condition B obtained reliably higher scores for central causal ideas, $F(1,152)=30.51, p<.01$; for secondary causal ideas, $F(1,152)=10.61, p<.01$; for the total of both types of causal ideas, $F(1,152)=22.622, p<.01$; and for organization, $F(1,152)=85.135, p<.01$. The students in Condition A included a significantly larger number of detail ideas, $F(1,152)=6.05, p=.01$. There was no difference between the two groups in the scores obtained for the inferential questions, $F(1,152)=0.052$, $p=.94$. The effect size was large for central causal ideas, total causal ideas, and organization; medium for secondary causal ideas; and small for detail ideas (see Note 10).

\section{Contribution of Word Recognition to Comprehension}

Table 4 shows the correlations between the measures included in the regression equations. We can see that all vari- ables showed a reliable correlation with the comprehension measures (central causal ideas plus secondary causal ideas). On the other hand, previous knowledge showed a highly significant correlation with rhetorical competence and word recognition.

Figure 2 shows the regression equation calculated for the interaction between joint reading and each one of the predictor variables (see Note 11): previous knowledge, rhetorical competence, working memory, and word recognition. As the figure shows, the variance explained by the equation is highly significant, and all the variables except working memory influence comprehension. On the other hand, there is no interaction between any of the variables and joint reading; that is, the weight of each of the variables did not differ significantly between one reading condition and another, although it is relevant to point out that the word recognition $\times$ joint reading interaction came closest to significance $(p=.09)$.

To enhance the picture offered by these results, we carried out an a posteriori comparative analysis of the comprehension level achieved by the pupils with most reading difficulties for both Condition A and Condition B. Specifically, we selected those students who met the following criteria:

1. They were slow at reading familiar words (taking 80 seconds, or $2 S D$ below the fifth-grade average, according to the PROLEC-SE measurement) or pseudowords (taking more than $104 \mathrm{~s}$, or 2 SD below the fifth-grade average).

2. They made more than 6 mistakes when reading familiar words (below the fifth-grade 10\%ile).

Two pupils were eliminated due to repeated absence, and one for bad behavior during the evaluation. The number of students finally selected was 17 (10 from Condition A and 7 from Condition B). Table 5 shows the descriptive information on these participants, with just one control variable added: students' intelligence (IQ), assessed by means of the Wechsler Intelligence Scale for Children-Revised.

Applying the Mann-Whitney $U$ test, it was shown that there were no significant differences between the pupils with low-level reading in Conditions $\mathrm{A}$ and $\mathrm{B}$ on any of the control variables (see Table 6); the $p$ values obtained from the Mann-Whitney $U$ test ranged from .17 to .96 . However, the Mann-Whitney $U$ tests showed that students with low-level reading in Condition B produced summaries with a significantly greater number of total causal $(U=10.50, p=.01)$ and central causal $(U=12.50, p=.03)$ ideas, although the differences in the other comprehension indicators were not statistically reliable (see Table 7). The effect size was large for total causal ideas, central causal ideas, secondary causal ideas, and organization, but in the last two measures there were no statistically significant differences; effect sizes were small for detail ideas and inferential questions.

Comparing these results with those reached by all the pupils in Condition A (i.e., not just those with low reading), it can be seen that pupils with low reading levels in Condition B at- 
TABLE 3

Means and Standard Deviations of Comprehension Indicator Measures by Group

\begin{tabular}{|c|c|c|c|c|c|c|c|c|}
\hline \multirow[b]{2}{*}{ Measure } & \multicolumn{2}{|c|}{ Condition A } & \multicolumn{2}{|c|}{ Condition B } & \multirow[b]{2}{*}{ Direction of difference } & \multicolumn{2}{|c|}{ Effect } & \multirow[b]{2}{*}{ Cl } \\
\hline & $M$ & $S D$ & $M$ & $S D$ & & $\delta$ & Size & \\
\hline Causal ideas (total) & 3 & 2 & 5 & 2 & $B>A^{* *}$ & 0.99 & large & $0.36-2.64$ \\
\hline Central causal ideas & 1.8 & 1.1 & 2.7 & 1.0 & $B>A^{* *}$ & 0.81 & large & $0.56-1.24$ \\
\hline Secondary causal ideas & 1.3 & 1.2 & 2.0 & 1.3 & $B>A^{* *}$ & 0.57 & medium & $0.30-1.10$ \\
\hline Inferential questions & 1.9 & 1.4 & 1.9 & 1.4 & no difference & - & no difference & $-0.45-0.45$ \\
\hline
\end{tabular}

Note. Condition $\mathrm{A}=$ traditional reading; Condition $\mathrm{B}=$ joint reading with Support Aids 1,2 , and $3 ; \mathrm{Cl}=$ confidence interval, $\alpha=.05$. $\mathrm{N}=77$ for both conditions. ${ }^{\star} p<.05 .{ }^{* *} p<.01$.

tained a level of comprehension equivalent to that reached by the whole group in the traditional reading condition (see Table 8). The Mann-Whitney, Kolmogorov-Smirnov, and $t$ tests only showed significant differences in the number of detail ideas contained in the summaries, $U=125.50, p=.02 ; \chi^{2}=$ 9.97, $p=.01 ; t(1,82)=2.20, p=.03 ;$ students with reading disabilities scored lower. Similarly, only for this variable was the effect size large $(\delta=0.82)$.

\section{Discussion}

Returning to our initial objectives, in light of our results, we ask ourselves (a) if the joint reading condition eliminated the effect of word recognition on comprehension or (b) if it permitted readers with $\mathrm{RD}$ to experience a typical comprehension level (i.e., similar to that usually experienced by their peers without RD). However, to assess the success of joint reading, it is advisable to check beforehand whether the pupils who read in this condition obtained a better level of comprehension.

\section{Does Joint Reading Improve the Comprehension Achieved by Participants?}

The data revealed that in Condition B, in which aids were offered before and during the reading of the text, pupils'

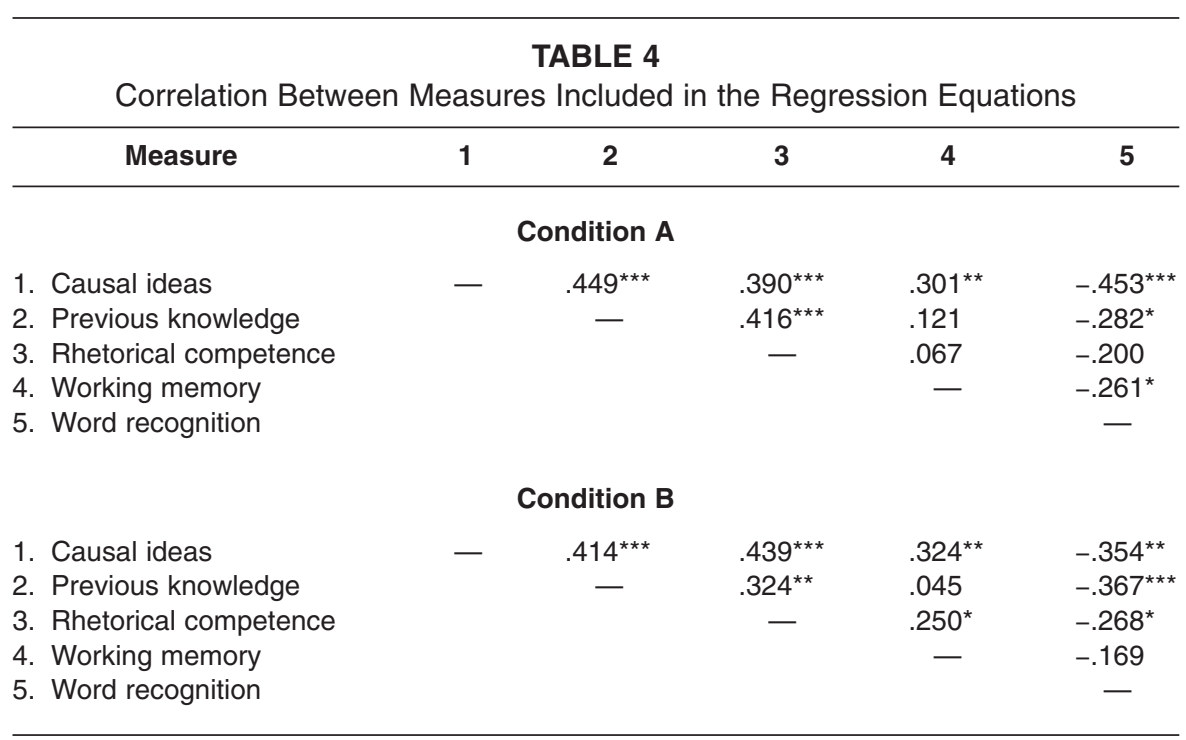

Note. Condition $\mathrm{A}=$ traditional reading; Condition $\mathrm{B}=$ joint reading with Support Aids 1,2 , and 3 . ${ }^{\star} p<.05 .{ }^{* *} p<.01 .{ }^{* * *} p<.001$.

$$
\begin{aligned}
& R^{2}=.44, p<.01 \\
& \text { Comprehension }=1.747^{\star}+.321 \mathrm{PK}^{\star}+.190 \mathrm{RC}^{\star}+.550 \mathrm{WM}-.027 \mathrm{WR}^{\star \star} \\
& \quad+.087(\mathrm{PK} \times \mathrm{JR})+.071(\mathrm{RC} \times \mathrm{JR})+.267(\mathrm{WM} \times \mathrm{JR})+.015(\mathrm{WR} \times \mathrm{JR})
\end{aligned}
$$

FIGURE 2. Regression equation calculated for the interaction between joint reading and each of the predictor variables. $\mathrm{PK}=$ previous knowledge; $\mathrm{RC}=$ rhetorical competence; $\mathrm{WM}=$ working memory; $\mathrm{WR}=$ word recognition; $\mathrm{JR}=$ joint reading. $\mathrm{PK} \times \mathrm{JR}, \mathrm{RC} \times \mathrm{JR}$, etc., indicate interactions between the respective variables. ${ }^{*} p<.05 .{ }^{* *} p<.01$.

comprehension was substantially reinforced. In more detailed terms, the students in Condition B (joint reading) reached the benchmarks set down to reflect adequate comprehension of the text, in that the number of causal ideas 


\section{TABLE 5}

Descriptive Statistics of Participants Selected for A Posteriori Comparative Analysis

\begin{tabular}{|c|c|c|c|c|c|}
\hline Participant & Gender & SES & IQ & Location & Condition \\
\hline 1 & female & low & 100.40 & rural & $A$ \\
\hline 2 & male & low & 85.00 & rural & A \\
\hline 3 & male & medium & 94.90 & urban & $A$ \\
\hline 4 & female & low & 103.20 & urban & $A$ \\
\hline 5 & male & medium & 116.00 & urban & $A$ \\
\hline 6 & male & medium & 96.80 & urban & $A$ \\
\hline 7 & male & medium & 105.00 & urban & $A$ \\
\hline 8 & female & low & 77.90 & rural & $A$ \\
\hline 9 & female & low & 57.50 & rural & $A$ \\
\hline 10 & male & low & 100.00 & urban & $A$ \\
\hline 11 & male & medium & 100.00 & rural & B \\
\hline 12 & female & low & 54.10 & rural & B \\
\hline 13 & male & low & 83.00 & rural & B \\
\hline 14 & male & low & 122.40 & urban & B \\
\hline 15 & female & low & 100.00 & urban & B \\
\hline 16 & male & medium & 104.80 & rural & $B$ \\
\hline 17 & female & medium & 58.00 & urban & B \\
\hline
\end{tabular}

Note. Condition A = traditional reading; Condition B = joint reading with Support Aids 1, 2, and 3; SES = socioeconomic status. All children selected were ages 11-12 years, in Grade 6, and in general education classrooms.

TABLE 6

Means and Standard Deviations of Intergroup Control Variables for Pupils With Reading Disabilities by Group

\begin{tabular}{|c|c|c|c|c|}
\hline \multirow[b]{2}{*}{ Variable } & \multicolumn{2}{|c|}{ Condition A } & \multicolumn{2}{|c|}{ Condition B } \\
\hline & $M$ & $S D$ & $M$ & $S D$ \\
\hline Previous knowledge & 2.2 & 1.2 & 1.7 & 1.8 \\
\hline Rhetorical competence & 5.0 & 1.5 & 3.9 & 2.8 \\
\hline Working memory & 1.2 & 0.6 & 1.6 & 0.5 \\
\hline $\begin{array}{l}\text { IQ } \\
\text { Access routes } \\
\text { Lexical }\end{array}$ & 93 & 13 & 88 & 25 \\
\hline $\begin{array}{l}\text { Accuracy } \\
\text { Speed }\end{array}$ & $\begin{array}{l}36.5 \\
93.1\end{array}$ & $\begin{array}{r}2.2 \\
32.2\end{array}$ & $\begin{array}{l}37.1 \\
91.1\end{array}$ & $\begin{array}{r}1.6 \\
38.0\end{array}$ \\
\hline $\begin{array}{c}\text { Phonological } \\
\text { Accuracy } \\
\text { Speed }\end{array}$ & $\begin{array}{r}31.0 \\
122.5\end{array}$ & $\begin{array}{l}3.9 \\
9.1\end{array}$ & $\begin{array}{r}32.1 \\
140.2\end{array}$ & $\begin{array}{r}5.9 \\
31.6\end{array}$ \\
\hline Comprehension & 7.2 & 4.2 & 6.0 & 5.0 \\
\hline
\end{tabular}

Note. Condition A = traditional reading; Condition $\mathrm{B}=$ joint reading with Support Aids 1,2 , and $3 . N=77$ for both conditions.

(central and secondary) exceeded the number of detail ideas and the organization of the summaries demonstrated causal logic (organization score higher than 2). However, given that the number of inferential questions answered correctly did not vary between conditions, it should be noted that the improvement in comprehension was relative: An adequate textual representation was achieved, but not an adequate situational representation. It is possible that the tasks employed for assessing situational representation were not the most appropriate, or that participants should have been offered more specific aids during the reading that invited them to integrate the text read with their previous knowledge (see Sánchez et al., 2006, for a more detailed discussion of these results).

\section{Does Joint Reading Eliminate the Impact of Word Recognition on Comprehension?}

Despite the value shown by the aids offered in Condition B (joint reading), they did not eliminate the effect of differences in reading speed on comprehension (see Figure 2). Moreover, the fact that word recognition continued to condition comprehension, in spite of readers being offered a context that facilitates text interpretation, reinforces the hypothesis that the two abilities are closely related, even in children with 6 years' schooling. Even so, this result does not rule out the possibility that the provision of different kinds of help-or simply more of it-would make the influence of word recognition cease to be significant. In fact, the result of the interaction between word recognition and reading condition (marginally significant) lends support to this possibility.

\section{Does Joint Reading Permit Readers With RD to Attain a Typical Level of Comprehension?}

The a posteriori analysis carried out with the participants who showed significant delay in the recognition of words produced two results that were both relevant:

1. The pupils with low-level reading assigned to the joint reading condition (Condition B) performed better than those that read the text without such aids in the variables considered critical (causal ideas and organization). 
TABLE 7

Means and Standard Deviations of Comprehension Indicator Measures for Pupils With Reading Disabilities by Group

\begin{tabular}{|c|c|c|c|c|c|c|c|c|}
\hline Measure & \multicolumn{2}{|c|}{ Condition $\mathrm{A}^{\mathrm{a}}$} & \multicolumn{2}{|c|}{ Condition $\mathrm{B}^{\mathrm{b}}$} & Direction of difference & \multicolumn{2}{|c|}{ Effect } & $\mathrm{Cl}$ \\
\hline Central causal ideas & 0.9 & 0.9 & 2.3 & 1.3 & $B>A^{*}$ & 1.43 & large & $0.20-2.60$ \\
\hline Secondary causal ideas & 0.4 & 0.7 & 1.3 & 1.1 & no difference & 1.18 & large & $-0.09-1.89$ \\
\hline Organization & 0.5 & 0.7 & 1.6 & 1.3 & no difference & 1.46 & large & $-0.01-2.21$ \\
\hline Inferential questions & 1.2 & 1.2 & 1.6 & 1.5 & no difference & 0.30 & small & $-1.09-1.89$ \\
\hline
\end{tabular}

Note. Condition $\mathrm{A}=$ traditional reading; Condition $\mathrm{B}=$ joint reading with Support Aids 1,2 , and $3 ; \mathrm{Cl}=$ confidence interval, $\alpha=.05$.

${ }^{a} n=10 .{ }^{b} n=7$.

${ }^{*} p<.05$.

TABLE 8

Comparison of Comprehension Indicators Between Pupils With Reading Disabilities in Condition B and the Whole Group in Condition A

\begin{tabular}{|c|c|c|c|c|c|c|c|c|}
\hline Variable & \multicolumn{2}{|c|}{ WG-A } & \multicolumn{2}{|c|}{ RD-B } & Direction of difference & \multicolumn{2}{|c|}{ Effect } & $\mathrm{Cl}$ \\
\hline Central causal ideas & 1.8 & 1.1 & 2.3 & 1.3 & no difference & 0.45 & small & $-0.40-1.40$ \\
\hline Secondary causal ideas & 1.3 & 1.2 & 1.3 & 1.1 & no difference & - & no difference & $-2.69-2.69$ \\
\hline Organization & 1.0 & 0.8 & 1.6 & 1.3 & no difference & 0.74 & medium & $-0.09-1.29$ \\
\hline Inferential questions & 1.9 & 1.4 & 1.6 & 1.5 & no difference & -0.21 & small & $-1.43-0.83$ \\
\hline
\end{tabular}

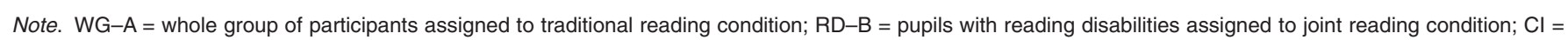
confidence interval, $\alpha=.05$.

${ }^{*} p<.05$.

2. More relevant for our purposes, the aids offered in Condition B permitted pupils with low-level reading to attain a comprehension level similar to that typically attained by readers with a higher level when they have no aids (Condition A, traditional reading).

Of course, the level reached by both pupils with low-level reading (with aids) and typical readers (without aids) is not optimal, but it at least provides pupils with low-level reading the opportunity to experience those moderate benefits (some degree of learning and comprehension, and perhaps also interest, awakened curiosity, satisfaction, escape, etc.) that reading usually provides to the typical reader.

We believe this result to be the most relevant because it is important to design reading conditions that guarantee communicative success, independently of how well or how poorly words are recognized. This would be especially important for the group of pupils with word recognition disabilities, as they are the least likely to be able to communicate through text and consequently will show the least tendency to enter into contact with text, in accordance with the Matthew effect (Stanovich, 1986).
Nevertheless, given that some of these results came from a posteriori analysis, and that neither in the total sample nor in that of students with RD did we distinguish between those with IQ higher than 85 and those with lower IQ, the results should be considered with caution, as a mere indication that the aids in Condition B (joint reading) also benefited (in the direction and with the magnitude predicted) the readers with lower recognition ability. Furthermore, given that the study was carried out in Spanish, it is necessary to exercise caution with regard to the generalization of these results to reading situations in other languages. Even so, 
joint reading may have the same effect in opaque spelling systems, such as that of English. Naturally, this is only a hypothesis, which should be explored empirically, even though we feel there are reasons to believe that the effect of joint reading in opaque systems might actually be more evident. Thus, in the case of English, the importance of morphological, syntactic, and semantic (i.e., not only phonological) knowledge for word recognition has been widely endorsed and demonstrated (e.g., Bryant, 2002; Sprenger-Charolles, 2004); likewise, there is support for a relationship between some of these variables and the greater benefit that the reader obtains from the reading context (Rego \& Bryant, 1993). Insofar as this is the case, joint readingprecisely because it provides additional contextual support-may minimize the effect of RD (to a greater extent than in Spanish) on optimizing the benefit obtained from readers' linguistic knowledge.

Finally, it is important to underline that joint reading, despite not neutralizing the effect of word recognition on comprehension (one more proof of the strength of this relationship), can serve to help the comprehension of each particular text, without demanding of readers any activity other than that of bringing into play the resources and knowledge they already have. Joint reading is, then, an activity that deliberately avoids pupils having to undertake new explicit learning and that seeks essentially that they be able to accede without delay to experiences that give meaning to contact with the written word. Nevertheless, and in the context of repeated joint reading experiences, pupils can gradually incorporate new resources or comprehension strategies; although this possibility has not been examined in this article, it has been dealt with in other studies.

If this argumentation is correct, it could be proposed that educational intervention with these pupils has the double dimension suggested. On the one hand, pupils with RD should be provided with the specific resources for improving their word recognition and comprehension ability; on the other hand, they should be helped to rediscover reading as a promising experience, ensuring an appropriate reading context in which their RD do not prevent them from appreciating the potential value of texts. The two dimensions can be organized strategically. For example, the intervention could begin with systematic group reading experiences to guarantee that pupils experience the purpose of written language before embarking on the hard road of specific treatment, which is where they would have to be provided with the necessary means. It needs hardly be stressed here that the two dimensions could complement and support one another throughout the long process of intervention (or literacy).

In sum, our aim was to test whether it is possible to create joint reading contexts through which pupils with difficulties in word recognition are able to enjoy the same opportunities for comprehension and pleasure as those available to students without RD. We believe that the data presented and the arguments outlined here endorse this possibility, and we suggest the need to enrich intervention in pupils with RD-even more so when the results obtained allow us at the same time to confirm the close relationship between word recognition and comprehension.

\section{ABOUT THE AUTHORS}

Emilio Sánchez is a professor of Educational Psychology in the Department of Developmental and Educational Psychology at the University of Salamanca (Spain). His research interests include reading disabilities, reader comprehension, educational consultation, and analysis of educational practice. José-Ricardo García is a lecturer of Educational Psychology and Reading Disabilities in the Department of Developmental and Educational Psychology at the University of Salamanca (Spain). His research interests include reading disabilities, reading comprehension, educational consultation, and analysis of educational practice. António-José Gonzalez is a lecturer of Psy- chology in the Higher Institute of Applied Psychology at Lisboa (Portugal). His research interests include reading comprehension, and teams' dynamic. Address: Emilio Sánchez Faculty of Education, Paseo de Canalejas, 169, 37008,Salamanca, Spain (e-mail: esanchez@ usal.es).

\section{AUTHORS' NOTES}

1. This work was carried out as part of a project financed by the Spanish Ministry of Science and Technology (BSO2002-03744) under the title: "Difficulties in Word Recognition, Joint Reading and Educational Intervention." Also, at the time of carrying out part of this work, José-Ricardo García was receiving a University Teachers Inservice Training grant from the Spanish Ministry of Education and Culture, and António-José Gonzalez was the recipient of a Science and Technology Foundation scholarship (XXI Praxis Program) from the Portuguese Ministry of Science and Technology.

2. The authors would like to thank the anonymous reviewers who, through their suggestions, have helped to improve this work.

\section{NOTES}

1. According to this perspective, competent readers invest fewer cognitive resources in low-level processes, thus allocating more resources to critical processes for achieving text comprehension. On the other hand, for poor readers, word recognition constitutes a "processing bottleneck": Their reading is so slow and laborious that it occupies attentional resources of which it deprives comprehension processes (Just \& Carpenter, 1987).

2. For example, according to estimations based on a study with fourth graders (Jenkins, Fuchs, van den Broek, Espin, E Deno, 2003a), children with good word recognition skills process a mean of 24.35 "idea units" per minute, compared to just 8.1 "idea units" processed by those with word recognition difficulties. As Jenkins et al. pointed out, it is easy to imagine how this difference will affect the temporal contiguity of the ideas in the text and, ultimately, the quality of text representation.

3. With regard to the study by Oakhill, Cain, and Bryant (2003), it is important to point out that the authors' decision was based on precise methodological criteria: Pupils with the lowest reading levels were eliminated from the sample because it was foreseen that 
they would have problems with most of the tasks set; the most competent readers, on the other hand, were eliminated in order to avoid a possible ceiling effect.

4. Something similar could be said in relation to comprehension problems, although the idea is less developed. Nonetheless, see Cain and Oakhill, 1999; Cain and Oakhill, 2004; Cain, Oakhill, and Bryant, 2000; and Sánchez, Gonzalez, and García, 2002.

5. If the hypothesis is supported, this will help in the redesign of the type of instruction relevant for children with dyslexia or delays in word recognition; if it is not supported, the indication will be that the impact of word recognition on comprehension is decisive, even when attempts are made to counteract this with comprehension aids.

6. We should highlight the fact that joint reading is indeed generalizable, in the sense that, with any given text, we can generate each one of the aids designed. Moreover, given that joint reading is not implicated in the specific processes of word recognition, it is valid in both transparent languages (e.g., Spanish) and in more opaque languages (e.g., English).

7. This study was part of a wider research project with a sample of 185 pupils, the total number of those enrolled in the sixth grade of the participating schools, excluding those who did not attend class during the research (four children). In the initial project, three reading contexts were designed (Sánchez, García, Gonzalez, and Herrera, 2006), but, given that one of the conditions did not affect comprehension, the data from this group were excluded.

8. In one of the schools it was not possible to assign the students at random because the headmaster preferred to maintain the class distribution already established. Nevertheless, the class groups had been formed alphabetically, which offered an equally random distribution. In fact, on comparing the average variables used as intergroup control it was confirmed that the groups were statistically equal.

9. In a normal educational situation it would be more natural to give this support orally.

10. The effect size was calculated with the standard deviation of the traditional reading group. The standardized mean difference was multiplied by the correction factor equalling 1 - 3/(4df - 1) (Hedges, 1981, in Olejnik \& Algina, 2000).

11. This equation was calculated as a hierarchical regression in which we introduced in first place previous knowledge, rhetorical competence, and working memory.

\section{REFERENCES}

Allor, J. H., Fuchs, D., \& Mathes, P. (2001). Do students with and without lexical retrieval weaknesses respond differently to instruction? Journal of Learning Disabilities, 34, 264-275.

Armbruster, B. B., Anderson, T. H., \& Ostertag, J. (1987). Does text structure/ summarization instruction facilitate learning expository text? Reading Research Quarterly, 22, 331-346.

Armbruster, B. B., Anderson, T. H., \& Ostertag, J. (1989). Teaching text structure to improve reading and writing. Reading Teacher, 42, 130-137.

Bell, L. C., \& Perfetti, C. A. (1994). Reading skill: Some adult comparisons. Journal of Educational Psychology, 86, 244-255.

Blachman, B. A., Schatschneider, C., Fletcher, J. M., Francis, D. J., Clonan, S. M., Shaywitz, B. A., et al. (2004). Effects of intensive reading remediation for second and third graders and 1-year follow-up. Journal of Educational Psychology, 96, 444461.

Bovair, S., \& Kieras, D. E. (1985). A guide to propositional analysis for research on technical prose. In B. K. Britton \& J. B. Black (Eds.), Understanding expository text (pp. 315-362). Hillsdale, NJ: Erlbaum.

Bowers, P., \& Wolf, M. (1993). Theoretical links among naming speed, precise timing mechanisms, and orthographic skill in dyslexia. Reading and Writing: An Interdisciplinary Journal, 5, 69-85.

Brown, R., Pressley, M., van Meter, P., \& Schuder, T. (1996). A quasi-experimental validation of transactional strategies instruction with low-achieving secondgrade readers. Journal of Educational Psychology, 88, 18-37.

Bryant, P. (2002). Children's thoughts about reading and spelling. Scientific Studies of Reading, 6, 199-216.

Cain, K., \& Oakhill, J. (1999). Inference making ability and its relation to comprehension failure in young children. Reading and Writing: An Interdisciplinary Journal, 11, 489-503.

Cain, K., \& Oakhill, J. (2004). Reading comprehension difficulties. In T. Nunes \& P. Bryant (Eds.), Handbook of children's literacy (pp. 313-338). Dordrecht: Kluwer.

Cain, K., Oakhill, J., \& Bryant, P. (2000). Investigating the causes of reading comprehension failure: The comprehensionage match design. Reading and Writing: An Interdisciplinary Journal, 12, 31-40.

Cain, K., Oakhill, J., \& Bryant, P. (2004).
Children's reading comprehension ability: Concurrent prediction by working memory, verbal ability, and component skills. Journal of Educational Psychology, 96, 31-42.

Calvo, A. (2000). Subtipos en lectores con dificultades en el aprendizaje de la lectura [Subtypes of children with difficulties in learning to read]. Unpublished doctoral dissertation, University of Murcia, Spain.

Catts, H. (1989). Defining dyslexia as a developmental language disorder. Annals of Dyslexia, 39, 50-76.

Cole, M. (1997). Cultural mechanism of cognitive development. In E. Amsel \& K. A. Renninger (Eds.), Change and development (pp. 245-263). Mahwah, NJ: Erlbaum.

Coltheart, M. (1978). Lexical access in simple reading tasks. In G. Underwood (Ed.), Strategies of information processing (pp. 151216). London: Academic Press.

Cuetos, F., Domínguez, A., Miera, G., \& de Vega, M. (1997). Diferencias individuales en el procesamiento léxico [Individual differences in lexical processing]. Estudios de Psicología, 57, 15-27.

Cuetos, F., \& Ramos, J. L. (1997). Batería de evaluación de los procesos lectores en el alumnado del tercer ciclo de educación primaria y educación secundaria obligatoria (PROLEC-SE) [Assessment battery for reading processes in older primary and secondary students]. Madrid: TEA.

Dole, J. A., Duffy, G. G., Roehler, L. R., \& Pearson, P. D. (1991). Moving from the old to the new: Research on reading comprehension instruction. Review of Educational Research, 61, 239-264.

Domínguez Martínez, A., \& Cuetos Vega, F. (1992). Desarrollo de las habilidades de reconocimiento de palabras en niños con distinta competencia lectora [Development of word recognition skills in children with different reading abilities]. Cognitiva, 4, 193-208.

Duffy, G. C., Roehler, L. R., Sivan, E., Rackliffe, G., Book, C., Meloth, M., et al. (1987). Effects of explaining the reasoning associated with using reading strategies. Reading Research Quarterly, 22, 347-368.

Elosúa, R., García Madruga, J. A., Gárate, M., Gutiérrez, F., \& Luque, J. L. (1993). Prueba de amplitud lectora [Reading span test]. Madrid: Universidad Nacional de Educación a Distancia.

Ellis, N. (1990). Reading, phonological skills and short-term memory: Interactive tributaries of development. Journal of Research in Reading, 13, 107-122.

Felton, R. H. (1992). Early identification of 
children at risk for reading disabilities. Topics in Early Childhood Special Education, 12, 212-229.

Fleisher, L., Jenkins, J., \& Pany, D. (1979). Effects on poor readers' comprehension of training in rapid decoding. Reading Research Quarterly, 15, 30-48.

Frederiksen, J. R., \& Warren, B. M. (1987). A cognitive framework for developing expertise in reading. In R. Glaser (Eds.), $A d-$ vances in instructional psychology (Vol. 3, pp. 1-39). Hillsdale, NJ: Erlbaum.

Graesser, A., \& Goodman, S. H. (1985). How to construct conceptual graph structures. In B. K. Britton \& J. B. Black (Eds.), Understanding expository text (pp. 363-383). Hillsdale, NJ: Erlbaum.

Graesser, A., \& Britton, B. (1996). Five metaphors for text understanding. In B. Britton \& A. Graesser (Eds.), Models of understanding text (pp. 341-352) Mahwah, NJ: Erlbaum.

Goldman, S. R., \& Rakestraw, J. A. (2000). Structural aspects of constructing meaning from text. In M. L. Kamil, P. B. Mosenthal, P. D. Pearson, \& R. Barr (Eds.), Handbook of reading research (Vol. III, pp. 311-335). Mahwah, NJ: Erlbaum.

Goodman, K. (1990). El lenguaje integral: Un camino fácil para el desarrollo del lenguaje [Whole language: An easy path to language development]. Lectura y Vida, 1(2), 1-13.

Gough, P. B., \& Tunmer, W. E. (1986). Decoding, reading, and reading disability. Peer Reviewed Journal, 7(1), 6-10.

Hatcher, P., Hulme, C., \& Ellis, A. (1994). Ameliorating early reading failure by integrating the teaching of reading and phonological skills: the phonological linkage hypothesis. Child Development, 65, 41-55.

Hernández-Valle, I., \& Jiménez, J. (2001). Conciencia fonémica y retraso lector: ¿Es determinante la edad en la eficacia de la intervención? [Phonemic awareness and delay in reading: Is age a determinant of the effectiveness of intervention?]. Infancia y Aprendizaje, 24, 379-395.

Jenkins, J. R., Barksdale, A., \& Clinton, L. R. (1978). Improving reading comprehension and oral reading: Generalization across behaviors, settings, and time. Journal of Learning Disabilities, 11(10), 5-14.

Jenkins, J. R., Fuchs, L. S., van den Broek, P., Espin, C., \& Deno, S. L. (2003a). Accuracy and fluency in list and context reading of skilled and RD Groups: Absolute and relative performance levels. Learning Disabilities Research E Practice, 18, 237-245.
Jenkins, J. R., Fuchs, L. S., van den Broek, P., Espin, C., \& Deno, S. L. (2003b). Sources of individual differences in reading comprehension and reading fluency. Journal of Educational Psychology, 95, 719-729.

Jiménez, J. E. (1997). A reading-level design study of phonemic processes underlying reading disabilities in a transparent orthography. Reading and Writing: An Interdisciplinary Journal, 9, 23-40.

Joanisse, M. F., Manis, F. R., Keating, P., \& Seidenberg, M. S. (1999). Language deficits in dyslexic children: Speech perception, phonology, and morphology. Journal of Experimental Child Psychology, 77, 30-60.

Joshi, R. M., \& Aarón, P. G. (2000). The component model of reading: Simple view of reading made a little more complex. Reading Psychology, 21, 85-97.

Just, M.A. \& Carpenter, P.A. (1987). The psychology of reading and language comprehension. Massachusetts: Allyn \& Bacon.

Klenk, L., \& Kibby, M. W. (2000). Remediating reading difficulties: Appraising the past, reconciling the present, constructing the future. In M. L. Kamil, P. B. Mosenthal, P. D. Pearson, \& R. Barr (Eds.), Handbook of reading research (Vol. III, pp. 667-690). Mahwah, NJ: Erlbaum.

Lovett, M. W., Borden, S. L., Deluca, T., Lacerenza, L., Benson, N. J., \& Brackstone, D. (1994). Treating the core deficits of developmental dyslexia: Evidence of transferof-learning following phonologically and strategy-based reading training programs. Developmental Psychology, 30, 805822.

Lovett, M. W., Steinbach, J. C., \& Frijters, J. (2000). Remediating the core deficits of developmental reading disability: A double-deficit perspective. Journal of Learning Disabilities, 33, 334-358.

Oakhill, J. V., Cain, K., \& Bryant, P. E. (2003). The dissociation of word reading and text comprehension: Evidence from component skills. Language and Cognitive Processes, 18, 443-468.

Olejnik, S., \& Algina, J. (2000). Measures of effect size for comparative studies: Applications, interpretations, and limitations. Contemporary Educational Psychology, 25, 241-286.

Olson, R. K., Wise, B., Ring, J., \& Johnson, M. (1997). Computer-based remedial training in phoneme awareness and phonological recoding: Effects on the posttraining development of word recognition. Scientific Studies of Reading, 1, 235253.

Palincsar, A. S., \& Brown, A. L. (1984). Rec- iprocal teaching of comprehension fostering and monitoring activities. Cognition and Instruction, 1, 117-175.

Peeck, J., van den Bosch, A. B., \& Kreupeling, J. W. (1982). Effect of mobilizing prior knowledge on learning from text. Journal of Educational Psychology, 74, 771-777.

Perfetti, C. A. (1985). Reading ability. New York: Oxford University Press.

Perfetti, C. A., \& Hogaboam, T. (1975). Relationship between single word decoding and reading comprehension skill. Journal of Educational Psychology, 67, 461-469.

Pressley, M. (1976). Mental imagery helps eight-year-olds remember what they read. Journal of Educational Psychology, 68, 355359.

Pressley, M. (1999). Cómo enseñar a leer [Reading instruction that works]. Barcelona: Paidós.

Pressley, M. (2000) What should comprehension instruction be the instruction of? In M. L. Kamil, P. B. Mosenthal, P. D. Pearson, \& R. Barr (Eds.), Handbook of reading research (Vol. III, pp. 545-561). Mahwah, NJ: Erlbaum.

Rack, J. P., Snowling, M. J., \& Olson, R. K. (1992). The non-word reading deficit in developmental dyslexia: A review. Reading Research Quarterly, 27, 29-53.

Rego, L. L. B., \& Bryant, P. E. (1993). The connection between phonological, syntactic and semantic skills and children's reading and spelling. European Journal of Psychology of Education, 8, 235-246.

Roehler, L. R., \& Duffy, G. G. (1984). Direct explanation of comprehension processes. In G. G. Duffy, L. R. Roehler, \& J. Mason (Eds.), Comprehension instruction: Perspectives and suggestions (pp. 265-280). New York: Longman.

Rueda, M. I., \& Sánchez, E. (1996). Relación entre conocimiento fonémico y dislexia: Un estudio instruccional [Relationship between phonemic knowledge and dyslexia: an instructional study]. Cognitiva, 8, 215-234.

Samuels, S. J., Dahl, P., \& Archwamety, T. (1974). Effects of hypothesis/test training on reading skill. Journal of Educational Psychology, 66, 835-844.

Sánchez, E. (1998). Comprensión y redacción de textos [Comprehension and writing of texts]. Barcelona: Edebé.

Sánchez, E., \& García, J. R. (2003). Los retos de la alfabetización: Cómo comprender lo que se lee cuando aún no se ha aprendido del todo a leer [The challenges of literacy: How to understand what one reads when one has not fully learned how 
to read]. Psicopedagogia: Revista da Associação Brasileira de Psicopedagogia, 20(62), 116-127.

Sánchez, E., García, J. R., Gonzalez, A. J. \& Herrera, P. (2006). The teaching of comprehension strategies from joint reading: Proposal and evidence. Manuscript in preparation.

Sánchez, E., Gonzalez, A. J., \& García, R. (2002). Competencia retórica: Una propuesta para interpretar las dificultades de comprensión [Rhetorical competence: A proposal for interpreting the difficulties of comprehension]. Psicothema, 14(1), 7785.

Sánchez, E., Rosales, J., \& Suárez, S. (1999). Interacción profesor/alumnos y comprensión de textos: Qué se hace y qué se puede hacer [Teacher/pupil interaction and text comprehension: What is done and what could be done]. Cultura y Educación, 14-15, 1-89.

Sánchez, E., \& Rueda, M. I. (1991). Segmental awareness and dyslexia: Is it possible to learn to segment well and yet continue to read and write poorly? Reading and Writing: An Interdisciplinary Journal, 3, 1118.

Sprenger-Charolles, L. (2004). Linguistic processes in reading and spelling: The case of alphabetic writing systems: English, French, German, and Spanish. In T. Nunes \& P. Bryant (Eds.), Handbook of children's literacy (pp. 43-66). Boston: Kluwer.

Stanovich, K. E. (1986). Matthew effects in reading: Some consequences of individual differences in the acquisition of literacy. Reading Research Quarterly, 21, 360407.

Stanovich, K. (1988). Explaining the differences between the dyslexic and garden variety poor reader: The phonological- core variable-difference model. Journal of Learning Disabilities, 21, 590-604.

Stanovich, K., \& Siegel, L. (1994). Phenotypic performance profile of children with reading disabilities: A regressionbased test of the phonological-core variable-difference model. Journal of Educational Psychology, 86, 24-53.

Swanson, H. L., \& Hovell, M. (2001). Working memory, short-term memory and speech rate as predictors of children's reading performance at different ages. Journal of Educational Psychology, 93, 720734.

Tan, A., \& Nicholson, T. (1997). Flashcards revisited: Training poor readers to read words faster improves their comprehension of text. Journal of Educational Psychology, 89, 276-288.

Troia, G. A. (1999). Phonological awareness intervention research: A critical review of the experimental methodology. Reading Research Quarterly, 34, 28-52.

Torgesen, J. K. (2002). The prevention of reading difficulties. Journal of School Psychology, 40(1), 7-26.

Torgesen, J. K., Wagner, R. K., Rashotte, C., Alexander, A. W., \& Conway, T. (1997). Preventive and remedial interventions for children with severe reading disabilities. Learning Disabilities: A Multidisciplinary Journal, 8, 51-61.

van den Bosch, K., van Bon, W., \& Schreuder, R. (1995). Poor readers' decoding skills: Effects of training with limited exposure duration. Reading Research Quarterly, 30, 110-125.

van Dijk, T. A., \& Kintsch, W. (1983). Strategies of discourse comprehension. New York: Academic Press.

Vidal-Abarca, E. (2002). Las dificultades de comprensión I: Diferencias en procesos de comprensión entre los lectores normales y con dificultades de comprensión [Comprehension difficulties I: Differences in comprehension processes between normal readers and those with comprehension difficulties] In A. Miranda, E. Vidal-Abarca, \& M. Soriano, Evaluación e intervención psicoeducativa en dificultades de aprendizaje [Psychoeducational assessment and intervention in learning difficulties] (pp. 129-156). Madrid: Pirámide.

Vellutino, F. R., Scanlon, D. M., \& Lyon, G. R. (2000). Differentiating between difficult-to-remediate and readily remediated poor readers. Journal of Learning Disabilities, 33, 223-238.

Wagner, R. K., \& Torgesen, J. K. (1987). The nature of phonological processing and its role in the acquisition of reading skills. Psychological Bulletin, 101, 192-212.

Wagner, R. K., Torgesen, J. K., \& Rashotte, C. (1994). The development of reading related phonological processing abilities: New evidence of bi-directional causality from a latent variable longitudinal study. Developmental Psychology, 30, 73-87.

Windfuhr, K. L., \& Snowling, M. J. (2001). The relationship between paired associate learning and phonological skills in normally developing readers. Journal of Experimental Child Psychology, 80, 160173.

Wolf, M. (1991). Naming speed and reading: The contribution of the cognitive neurosciences. Reading Research Quarterly, 26, 123-141.

Wolf, M., \& Bowers, P. (1999). The double deficit hypothesis for the developmental dyslexias. Journal of Educational Psychology, 91, 415-438. 
Copyright of Journal of Learning Disabilities is the property of PRO-ED and its content may not be copied or emailed to multiple sites or posted to a listserv without the copyright holder's express written permission. However, users may print, download, or email articles for individual use. 